\title{
Three-Dimensional Coherent Titania-Mesoporous Carbon Nanocomposite and Its Lithium-Ion Storage Properties
}

\author{
Laifa Shen, ${ }^{\dagger \dagger}$ Evan Uchaker, ${ }^{\ddagger}$ Changzhou Yuan, ${ }^{\dagger}$ Ping Nie, ${ }^{\dagger}$ Ming Zhang, ${ }^{\ddagger}$ Xiaogang Zhang, ${ }^{*}{ }^{\dagger}$ \\ and Guozhong Cao* $\$$
}

${ }^{\dagger}$ College of Material Science \& Engineering, Nanjing University of Aeronautics and Astronautics, Nanjing, 210016, People’s Republic of China

${ }^{\ddagger}$ Department of Materials Science and Engineering, University of Washington, Seattle, Washington, 98195, the United States.

\section{Supporting Information}

ABSTRACT: Mesoporous, micro/nanosized $\mathrm{TiO}_{2} / \mathrm{C}$ composites with uniformly dispersed $\mathrm{TiO}_{2}$ nanoparticles embedded in a carbon matrix have been rationally designed and synthesized. In brief, $\mathrm{TiO}_{2}$ precursor was infiltrated into the channels of surfaceoxidized mesoporous carbon (CMK-3) by means of electrostatic interaction, followed by in situ hydrolysis and growth of $\mathrm{TiO}_{2}$ nanocrystallites, resulting in ultrafine $\mathrm{TiO}_{2}$ nanoparticle confined inside the channels of mesopores carbon. After chemical lithiation and post-annealing, $\mathrm{TiO}_{2}$ nanoparticles were transformed in situ into $\mathrm{Li}_{4} \mathrm{Ti}_{5} \mathrm{O}_{12}$ to form highly conductivity mesoporous $\mathrm{Li}_{4} \mathrm{Ti}_{5} \mathrm{O}_{12} / \mathrm{C}$ composite, as confirmed by scanning electron microscope (SEM), transmission electron microscopy (TEM), X-ray diffraction (XRD), Raman spectroscopy, and nitrogen sorption isotherms. By combining high electronic conductivity, open mesoporosity, and nanosized active material, coherent mesoporous $\mathrm{TiO}_{2} / \mathrm{C}$ and $\mathrm{Li}_{4} \mathrm{Ti}_{5} \mathrm{O}_{12} / \mathrm{C}$ nanocomposites demonstrated high rate capability and good cycling properties.

KEYWORDS: $\mathrm{TiO}_{2}, \mathrm{Li}_{4} \mathrm{Ti}_{5} \mathrm{O}_{12}$ ordered mesoporous structure, lithium ion batteries

\section{INTRODUCTION}

Lithium ion batteries (LIBs) have been regarded as one of the most promising candidates for applications in electric and hybrid vehicles with the potential to save oil and reduce $\mathrm{CO}_{2}$ emissions, although they still suffer from low power density and safety concerns. ${ }^{1-4}$ Conventional graphitic carbons used as anodes in commercial LIBs exhibits poor rate performance induced by its low Li diffusion coefficient. ${ }^{5}$ Because of the lower operating voltage, solid-electrolyte interface (SEI) film and dendritic lithium are easily formed on the surface of graphite anode, which would cause serious safety issues and poor cycle life. ${ }^{6-10}$ The commercial LIBs are inadequate to meet high power applications, advanced materials with better safety and high rate capability are critical for next-generation LIBs.

Titanium-based compounds are promising candidates as alternative materials to carbonaceous anodes, because of not only its structural characteristics and special surface activity but also its low cost, safety, and environmental benignity. ${ }^{11-18}$ Typically, the $\mathrm{Li}^{+}$insertion/extraction reaction for $\mathrm{TiO}_{2}$ polymorphs occurs in the potential range of $1.4-1.8 \mathrm{~V}$ vs $\mathrm{Li}$ / $\mathrm{Li}^{+}$, according to the following reaction

$$
x \mathrm{Li}^{+}+\mathrm{TiO}_{2}+x \mathrm{e}^{-}=\mathrm{Li}_{x} \mathrm{TiO}_{2}(0 \leq x \leq 1)
$$

Because of low packing density, anatase (density, $\rho=3.89 \mathrm{~g}$ $\left.\mathrm{cm}^{-3}\right)$ and $\mathrm{TiO}_{2}-\mathrm{B}\left(\rho=3.73 \mathrm{~g} \mathrm{~cm}^{-3}\right)$ phases show higher lithium storage capacity as compared to densely packed

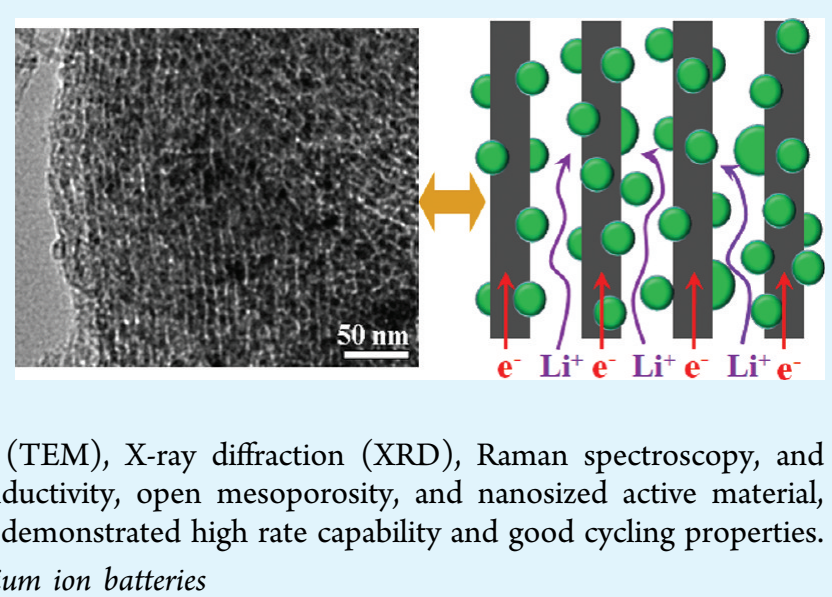

brookite $\left(\rho=4.13 \mathrm{~g} \mathrm{~cm}^{-3}\right)$ and rutile $\left(\rho=4.25 \mathrm{~g} \mathrm{~cm}^{-3}\right)$ phases, both anatase $\mathrm{TiO}_{2}$ and $\mathrm{TiO}_{2}-\mathrm{B}$ have been extensively investigated as potential alternative anode material for LIBs. ${ }^{19,20}$ Anatase $\mathrm{TiO}_{2}$ is known to be a electrochemically active with a capacity of about 0.6 lithium ion in $\mathrm{Li}_{x} \mathrm{TiO}_{2}$ at $1.78 \mathrm{~V}$ vs $\mathrm{Li} / \mathrm{Li}^{+}$. $\mathrm{TiO}_{2}-\mathrm{B}$ is the least dense polymorph of $\mathrm{TiO}_{2}$, and has a theoretical capacity of $335 \mathrm{~mA} \mathrm{~h} \mathrm{~g}{ }^{-1}$. $\mathrm{TiO}_{2}-\mathrm{B}$ has an open structure with freely accessible channels for Li-ion transport perpendicular to the (010) face, which allows easy Li-ion transport. It has been demonstrated that the kinetics of lithiumion storage in $\mathrm{TiO}_{2}-\mathrm{B}$ is governed by a pseudocapacitive Faradaic process, which is not limited by solid-state diffusion of $\mathrm{Li}$ ions. ${ }^{21-23}$ The spinel, $\mathrm{Li}_{4} \mathrm{Ti}_{5} \mathrm{O}_{12}$, reversibly accepts three $\mathrm{Li}^{+}$ per formula unit with a two-phase equilibrium for $175 \mathrm{~mA} \mathrm{~h} \mathrm{~g}^{-1}$ insertion at $1.55 \mathrm{~V}$ vs $\mathrm{Li} / \mathrm{Li}^{+}$. Additionally, the spinel $\mathrm{Li}_{4} \mathrm{Ti}_{5} \mathrm{O}_{12}$, as a zero-strain insertion material, possesses excellent reversibility and structural stability during the charge-discharge process, which makes the $\mathrm{Li}_{4} \mathrm{Ti}_{5} \mathrm{O}_{12}$ particularly attractive for large scale energy storage. ${ }^{24-30}$

Unfortunately, the rate performance of bulk titania and $\mathrm{Li}_{4} \mathrm{Ti}_{5} \mathrm{O}_{12}$ material is greatly limited due to the poor electronic and ionic conductivity, which constitutes a major obstacle for

Received: February 27, 2012

Accepted: May 25, 2012

Published: May 25, 2012 
Scheme 1. Schematic Illustration of the Synthesis of MMN-TO/C and MMN-LTO/C

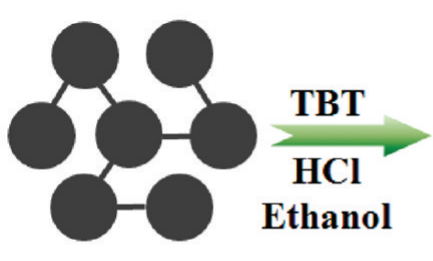

CMK-3 Impregnation sucrose solution Carbonization Removing silica

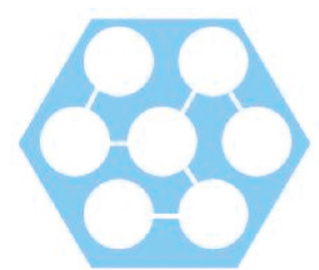

SBA-15

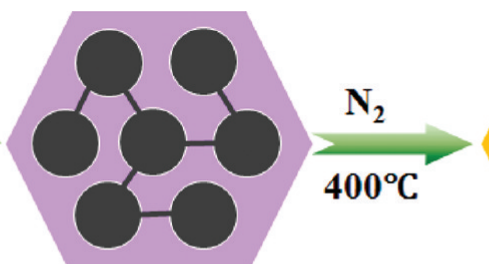

Ti-O-CMK-3

LiOH solution

$60^{\circ} \mathrm{C}$
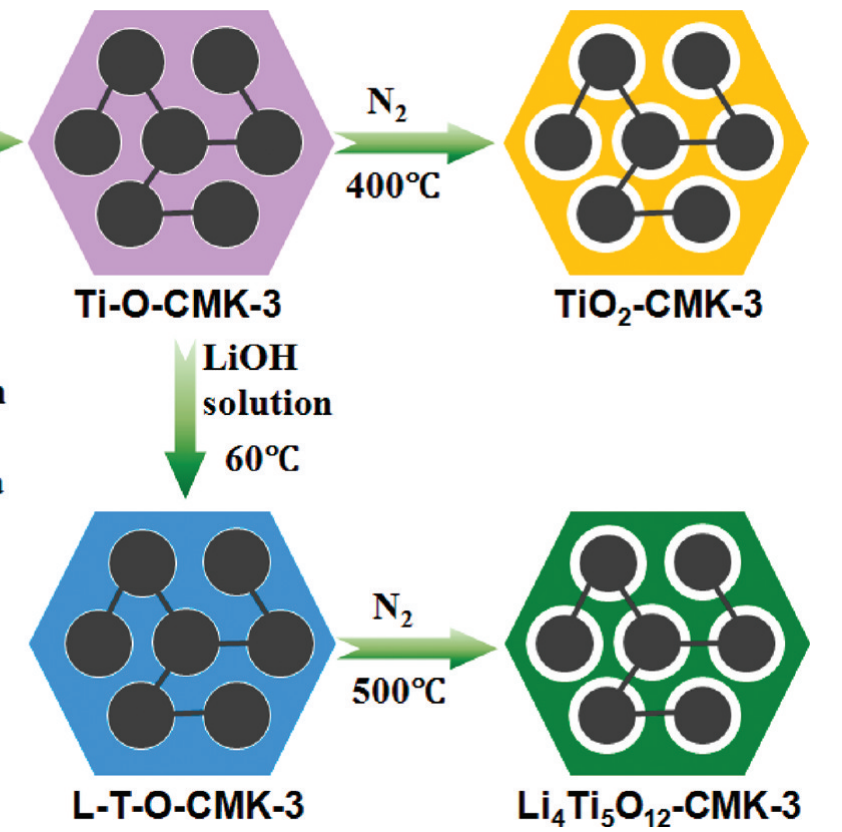

its practical application. ${ }^{31-35}$ Two main approaches have been developed to improve the electronic conductivity. One way is the addition of conductive secondary phases, such as conductive carbon, ${ }^{36,37}$ or noble metals (such as $\mathrm{Ag}$ ), ${ }^{38}$ or oxides (such as $\left.\mathrm{RuO}_{2}\right){ }^{39}$ Although noble metals and oxides could improve electronic conductivities, they do increase the cost of the active materials and reduce the weight fraction of active materials. The other way is to dope the active materials with heteroatoms sacrificing cycle life. ${ }^{40}$ Tailoring the particle size from micrometer to nanometer is a key to improved $\mathrm{Li}^{+}$ diffusion, because of the reduced diffusion length. ${ }^{41-43}$ The fabrication of nanosized particles is still a challenge by using solid-state reaction or sol-gel methods because the conventional synthesis routes require high temperature treatment to achieve phase-pure lithium titanate. Wet chemical synthesis is among the best choices for the preparation of nanocrystallite $\mathrm{Li}_{4} \mathrm{Ti}_{5} \mathrm{O}_{12} \cdot{ }^{44,45} \mathrm{We}$ have reported the synthesis of $\mathrm{Li}_{4} \mathrm{Ti}_{5} \mathrm{O}_{12} /$ carbon nanotube ${ }^{38}$ and $\mathrm{Li}_{4} \mathrm{Ti}_{5} \mathrm{O}_{12} /$ graphene nanocomposite ${ }^{28}$ by using this method, which show enhanced charge transfer kinetics. However, nanosized materials are difficult to make electrodes and suffer from lower volumetric density than micrometer-sized materials. It is also more difficult to maintain efficient electron transport between the current collector and the active materials, because of more contacts that must be preserved against a background of nanosized particles. ${ }^{46}$ To acquire an optimized electrochemically performance by using nanosized materials, it is desirable to create a micrometer-sized conductive matrix that enables fast electron transport between nanoparticles. Further improvement can be achieved by introducing high porosity and high specific surface area. ${ }^{47,48}$ The mesoporous materials offer fast ion/electron transfer and sufficient contact between active materials and electrolyte, resulting in a large lithium storage capacity and high insertion rates. CMK-3, a highly conductive mesoporous carbon with desirable characteristics, has attracted much attention for used as conductive and porous matrix for LIBs. ${ }^{49-51}$ However, the synthesis and lithium-ion storage properties of order mesoporous $\mathrm{TiO}_{2} / \mathrm{C}$ and $\mathrm{Li}_{4} \mathrm{Ti}_{5} \mathrm{O}_{12} / \mathrm{C}$ has been very limited. Ishii et al. synthesized mesoporous $\mathrm{TiO}_{2} / \mathrm{C}$ by triconstituent

coassembly method using copolymer, Pluronic F127, as soft template. ${ }^{52}$ Kang and co-worker reported a mesostructured spinel $\mathrm{Li}_{4} \mathrm{Ti}_{5} \mathrm{O}_{12}$-carbon nanocomposite via the similar method. ${ }^{53}$ The improvement of electronic conductivity is limited because the lower temperature calcinations in order to preserve their ordered structures.

In this paper, we report an ordered mesoporous, micro/ nanosized $\mathrm{TiO}_{2} / \mathrm{C}$ composite $(\mathrm{MMN}-\mathrm{TO} / \mathrm{C})$ by a nanocasting technique using $\mathrm{CMK}-3$ as template and tetrabutyl titanate (TBT) as precursor, in which $\mathrm{TiO}_{2}$ nanoparticles are embedded in the mesopores of carbon matrix. The mesoporous, micro/nanosized $\mathrm{Li}_{4} \mathrm{Ti}_{5} \mathrm{O}_{12} / \mathrm{C}$ (MMN-LTO/C) were in situ formed by chemical lithiation of $\mathrm{MMN}-\mathrm{TO} / \mathrm{C}$, followed with postannealing. In this "meso-micro/nano" composite electrode, the CMK-3 not only serves as conductive matrix that enables fast electron transport, but also prevents nanocrystal growth during the calcination process. Furthermore the mesoporous structure may facilitate the contact of nanoactive material with electrolyte. When tested as potential anode materials for LIBs, the "meso-micro/nano" composite electrode exhibits excellent rate capability and good cycling properties at high rates.

\section{EXPERIMENTAL SECTION}

Materials Synthesis. CMK-3 was prepared using SBA-15 as template, which is further described in the Supporting Information. In brief, $0.2 \mathrm{~g}$ of CMK-3 template powder was refluxed in $6 \mathrm{M} \mathrm{HNO}_{3}$ solution under stirring for $1 \mathrm{~h}$ at $80{ }^{\circ} \mathrm{C}$ to make the powder more easily dispersible in ethanol. In a typical process, $1.0 \mathrm{~g}$ of concentrated $\mathrm{HCl}$ was slowly added to $1.9 \mathrm{~mL}$ of tetrabutyl titanate (TBT) under vigorous stirring. Meanwhile, $0.1 \mathrm{~g}$ of acid-treated CMK-3 was ultrasonically dispersed in $10 \mathrm{~mL}$ of ethanol. After ultrasonic treatment, the mixture of $\mathrm{TBT} / \mathrm{HCl}$ was added to the above solution with vigorous stirring for 2 days to ensure the complete infiltration of pores. The mixture was then dried and ground. The powder was sintered at $400{ }^{\circ} \mathrm{C}$ for $2 \mathrm{~h}$ in a nitrogen atmosphere to obtain MMNTO/C. For the preparation of MMN-LTO/C, $0.5 \mathrm{~g}$ dried powder was dispersed in a $2.0 \mathrm{M} \mathrm{LiOH}$ aqueous solution and kept at $60^{\circ} \mathrm{C}$ for $10 \mathrm{~h}$. The black precipitate was then separated by filtration and washed with high-purity water several times to remove an excess of hydroxides 
before drying at $60{ }^{\circ} \mathrm{C}$ for $12 \mathrm{~h}$. Subsequently, the black powder was sintered at $500{ }^{\circ} \mathrm{C}$ for $2 \mathrm{~h}$ in a nitrogen atmosphere to obtain MMN$\mathrm{LTO} / \mathrm{C}$.

Materials Characterization. The crystal structure of the obtained samples was characterized by X-ray diffraction (XRD) (Bruker D8 advance) with $\mathrm{Cu} \mathrm{Ka}$ radiation. Microstructural properties were determined using transmission electron microscopy (TEM, FEI, Tecnai-20, USA), and field-emission scanning electron microscopy (FESEM, LEO 1430VP, Germany). The composition of the samples was analyzed by energy dispersive X-ray spectroscopy (EDX) attached to the FESEM instrument. The $\mathrm{N}_{2}$ adsorption/desorption were determined by Brunauer-Emmett-Teller (BET) measurements using an ASAP-2010 surface area analyzer. Raman spectra were collected using a Renishaw 2000 system with an argon ion laser $(514.5 \mathrm{~nm})$ and charge-coupled device detector. Thermogravimetric analysis was performed on a TG instrument (NETZSCH STA 409 PC).

Electrochemical Measurement. The electrochemical characterization was carried out by galvanostatic cycling in a two-electrode electrochemical cell. The working electrode was prepared by a slurry coating procedure. The slurry consisted of $85 \mathrm{wt} \%$ active material, 5 wt $\%$ acetylene black, and 10 wt $\%$ polyvinylidene fluoride (PVDF) dissolved in $\mathrm{N}$-methyl pyrrolidinone (NMP), and was uniformly spread on an aluminum foil current collector. Finally, the electrode was dried under vacuum at $110{ }^{\circ} \mathrm{C}$ for $12 \mathrm{~h}$. The typically mass loading of active materials is about $9 \mathrm{mg} \mathrm{cm}{ }^{-2}$. Test cells were assembled in an argon-filled glovebox using $\mathrm{Li}$ foil as the counter electrode and polypropylene (PP) film as separator. A $1 \mathrm{~mol} \mathrm{~L}^{-1} \mathrm{LiPF}_{6}$ solution in a 1:1 (V:V) mixture of ethylene carbonate (EC) and dimethyl carbonate (DMC) was used as electrolyte. The cells were galvanostatically charged and discharged under different current densities between 1.0 and $3.0 \mathrm{~V}\left(\mathrm{vs} \mathrm{Li} / \mathrm{Li}^{+}\right.$) using an Arbin Battery Tester BT-2000 (Arbin Instruments, College Station, Texas). Cyclic voltammetry (CV) studies were carried out on an electrochemical workstation (CHI $660 \mathrm{C}$ ) between 1.0 and $3.0 \mathrm{~V}$ at a scan rate of $0.5 \mathrm{mV} \mathrm{s}^{-1}$.

\section{RESULTS AND DISCUSSION}

The fabrication process for $\mathrm{MMN}-\mathrm{TO} / \mathrm{C}$ composites is depicted in Scheme 1. The ordered mesoporous carbon CMK-3 was synthesized by replication using SBA-15 as template and sucrose as carbon source followed by a surface oxidation in $6 \mathrm{M} \mathrm{HNO}_{3}$ to obtain the functionalized carbon matrix. The functional oxygenated groups on carbon surfaces not only gives rise to a hydrophilic surface but also drives the facile infiltration of precursors in the pores because of interaction with metal ions, leading to an easy and full loading of precursors into the whole mesopore system. The precursors are first converted into amorphous $\mathrm{TiO}_{2}$ network by in situ controlled hydrolysis in the presence of $\mathrm{HCl}$. A subsequent step through heat treatment at $400{ }^{\circ} \mathrm{C}$ leads to crystallization of the $\mathrm{TiO}_{2}$ and release of porosity, resulting in ultrafine $\mathrm{TiO}_{2}$ nanoparticle confined in the connected mesopores carbon channels. The $\mathrm{TiO}_{2}$ nanoparticles embedded in mesoporous carbon matrix were transformed in situ into $\mathrm{Li}_{4} \mathrm{Ti}_{5} \mathrm{O}_{12}$ by chemical lithiation and a short post-annealing procedure to form highly conductivity MMN-LTO/C.

The chemical composition of the samples was characterized by using X-ray diffraction (XRD; Figure 1). Figure 1a shows the XRD pattern of $\mathrm{MMN}-\mathrm{TO} / \mathrm{C}$, demonstrated a majority anatase $\mathrm{TiO}_{2}$ (JCPDS 84-1285) phase, with a small fraction of $\mathrm{TiO}_{2}-\mathrm{B}$ phase (JCPDS 35-0088). The MMN-LTO/C synthesized by chemical lithiation of $\mathrm{MMN}-\mathrm{TO} / \mathrm{C}$ exhibits good crystallinity and a typical spinel structure after annealing in $\mathrm{N}_{2}$ at $500{ }^{\circ} \mathrm{C}$, which is in accordance with those established by JCPDS card number 49-0207 (Figure 1b). By using Scherrer's formula based on the (101) peak for $\mathrm{TiO}_{2}$ and (111) peak for $\mathrm{Li}_{4} \mathrm{Ti}_{5} \mathrm{O}_{12}$, the grain size of nanoparticles is estimated
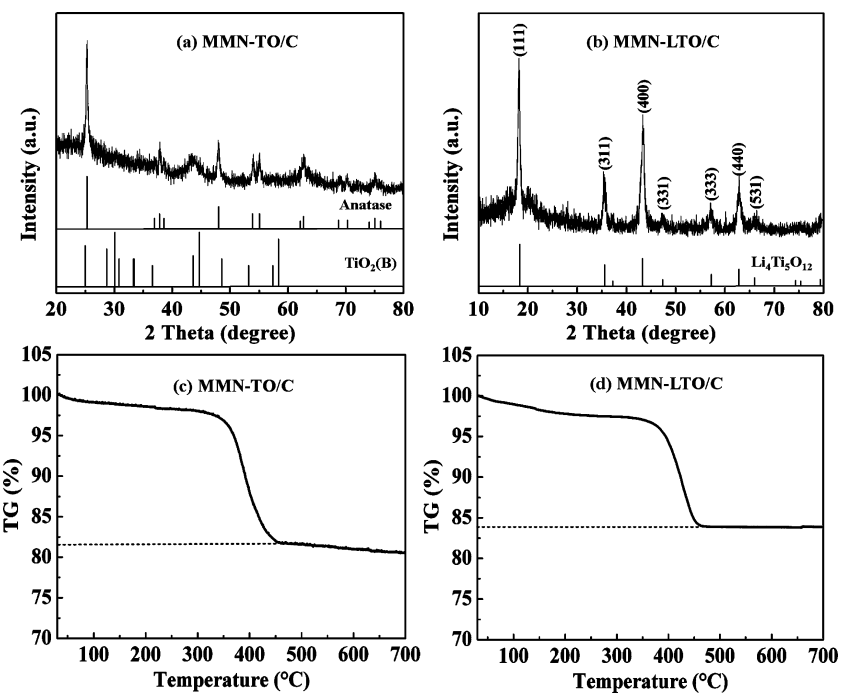

Figure 1. XRD patterns of (a) MMN-TO/C, (b) MMN-LTO/C, TGA curves of (c) MMN-TO/C, (d) MMN-LTO/C.

to be about 6 and $9 \mathrm{~nm}$ for MMN-TO and MMN-LTO, respectively. No obvious peaks corresponding to graphite are found in the XRD pattern of MMN-LTO/C, indicating the carbon in the sample is not well crystallized. This could be confirmed by a Raman spectroscopy measurement, which is shown in Figure S1 in the Supporting Information. The two strong bands around 1380 and $1590 \mathrm{~cm}^{-1}$ are attributed to the in-plane vibration of disordered amorphous carbon ( $\mathrm{D}$ band) and crystalline graphic carbon ( $G$ band), respectively. The intensity ratio $\left(I_{\mathrm{D}} / I_{\mathrm{G}}\right)$ of the two bands is 1.39 , verifying the low and close graphitization degree of the as-obtained composite. ${ }^{54}$ The weight fraction of CMK-3 template in the two hybrid materials was determined by thermogravimetric analysis (TGA), with the results shown in Figure 1c, d. The obvious weight loss at around $400{ }^{\circ} \mathrm{C}$ for both samples was caused by the combustion of CMK-3 in air. The amount of carbon in MMN-TO/C and MMN-LTO/C is about 18.4 and 16.2 wt \%, respectively.

Scanning electron microscopy (SEM) and transmission electron microscopy (TEM) were employed to investigate the morphology and structure of the different materials obtained. Representative SEM images (Figure 2a) reveal that CMK-3 template has a rodlike morphology, as that of the mesoporous silica SBA-15. ${ }^{55}$ The mesoporous channels of CMK-3 template in [100] directions is clearly visible in Figure $2 \mathrm{~b}$. Image taken from [001] direction confirms the 2-D hexagonal symmetrical mesostructure with uniform pore size of about $4 \mathrm{~nm}$ (insert in Figure $2 \mathrm{~b}$ ), which is in good agreement with that measured from BET. The MMN-TO/C obtained by controlled hydrolysis of TBT in the mesopore carbon channel (Figure 2c). The uniform dispersed of the $\mathrm{TiO}_{2}$ nanoparticles in the carbon matrix is further confirmed by the TEM image shown in Figure 2 d, where $\mathrm{TiO}_{2}$ nanoparticles highlighted by red arrows are embedded in mesopore channels as well as uniformly dispersed on the surface of CMK-3. The chemical composition of the products has been analyzed by energy-dispersive X-ray (EDX) spectroscopy (see Figure S2 in the Suporting Information), which confirms the existence of $\mathrm{C}, \mathrm{Ti}$ and $\mathrm{O}$. After chemical lithiation and a short post-annealing procedure, the MMN-TO/C was transformed in situ into MMN-LTO/ $\mathrm{C}$, which maintains the same shape and morphology as that of 


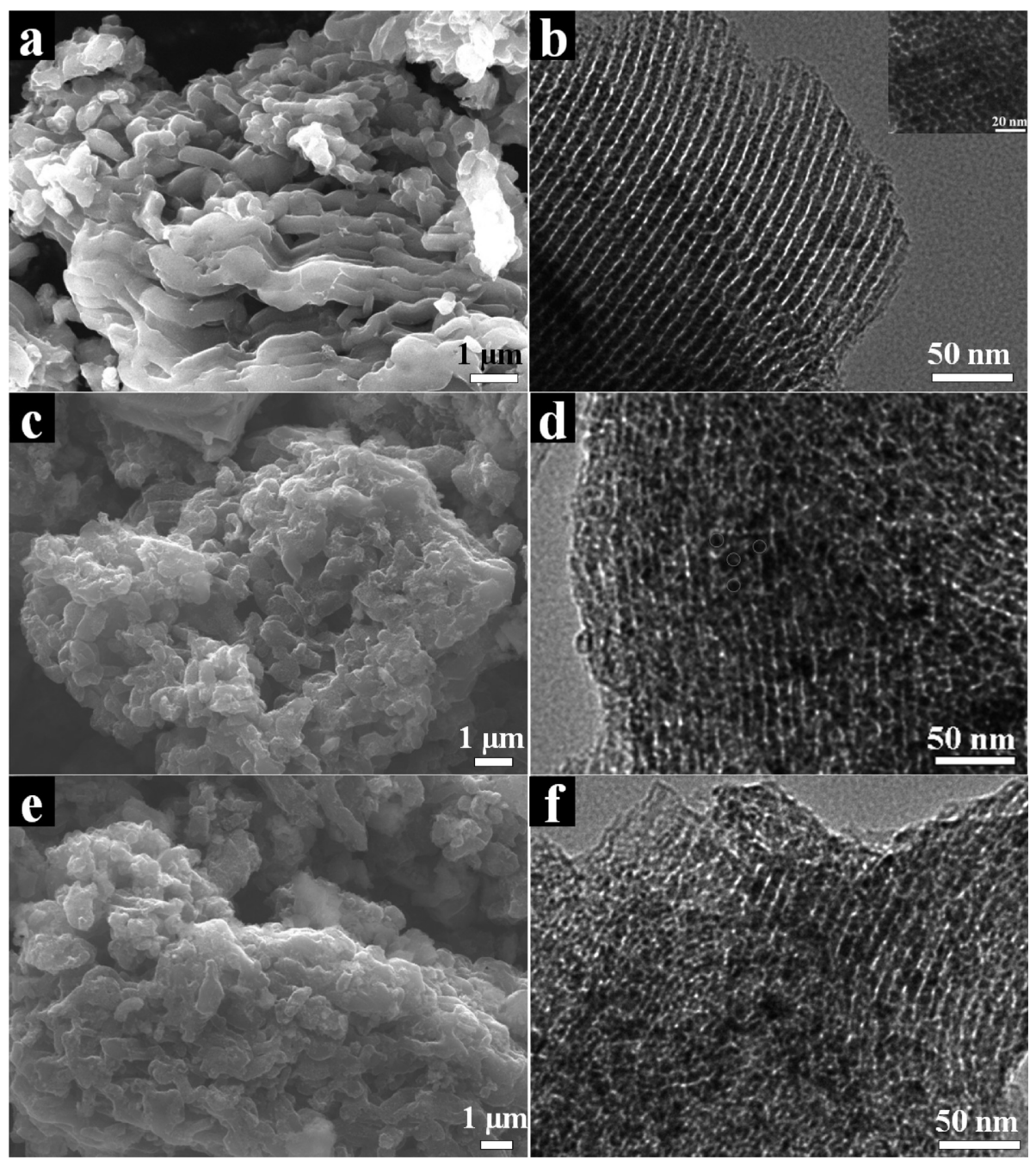

Figure 2. (a) SEM image and (b) TEM image of CMK-3 template, (c) SEM image and (d) TEM image of MMN-TO/C, (e) SEM image and (f) TEM image of MMN-LTO/C.

the MMN-TO/C (Figure 2e, f). From a high-magnification TEM image (see Figure S3 in the Supporting Infomration), the size of LTO nanoparticle is about $10 \mathrm{~nm}$, which is in agreement with the XRD result.

The in situ hydrolysis and crystallization of the loaded precursors to oxides is accompanied by significant volume shrinkage, with part the preoccupied pore space by the precursors being released after the conversion. As a result, the MMN-TO/C and MMN-LTO/C still possess high mesoporosity and an open pore system. Brunauer-EmmettTeller (BET) gas-sorption measurements were performed to further investigate the specific surface areas and the porous nature of the CMK-3 template, MMN-TO/C and MMNLTO/C. Nitrogen adsorption-desorption isotherms of the CMK-3 template are found to be type IV according to the IUPAC classification and exhibits a typical $\mathrm{H} 1$ hysteresis loop in the $P / P_{0}$ range of $0.4-0.6$ (see Figure $S 4$ in the Supporting Information). ${ }^{56}$ The pore size distribution (PSD) measurements reveals that the CMK-3 template has a very narrow poresize distribution centered at ca. $4.1 \mathrm{~nm}$. Most of $\mathrm{TiO}_{2}$ $\left(\mathrm{Li}_{4} \mathrm{Ti}_{5} \mathrm{O}_{12}\right)$ nanocrystals are loaded in the connected mesopores channel, as confirmed by TEM. The surface area and pore volume of are $\mathrm{MMN}-\mathrm{TO} / \mathrm{C}$ and $\mathrm{MMN}-\mathrm{LTO} / \mathrm{C}$, not surprisingly, significantly decreased. As listed in Table 1 , the
Table 1. Textural Properties of CMK-3 Template, MMNTO/C and MMN-LTO/C

\begin{tabular}{lcc} 
sample name & BET surface area $\left(\mathrm{m}^{2} \mathrm{~g}^{-1}\right)$ & pore volume $\left(\mathrm{cm}^{3} \mathrm{~g}^{-1}\right)$ \\
CMK-3 & 1083 & 1.008 \\
MMN-TO/C & 211.3 & 0.212 \\
MMN-LTO/C & 189.4 & 0.190 \\
\hline
\end{tabular}

BET surface area and single point total pore volume of CMK-3 template are determined to be $1083 \mathrm{~m}^{2} \mathrm{~g}^{-1}$ and $1.008 \mathrm{~cm}^{3} \mathrm{~g}^{-1}$, respectively. After incorporation of titanium-based nanoparticles in the pores of CMK-3, the BET surface area of MMN-TO/C and MMN-LTO/C was decreased to $211.3 \mathrm{~m}^{2}$ $\mathrm{g}^{-1}, 189.4 \mathrm{~m}^{2} \mathrm{~g}^{-1}$, accompanied by a decrease in pore volume, $0.212 \mathrm{~cm}^{3} \mathrm{~g}^{-1}, 0.190 \mathrm{~cm}^{3} \mathrm{~g}^{-1}$, respectively. The corresponding pore size distribution curves of $\mathrm{MMN}-\mathrm{TO} / \mathrm{C}$ and $\mathrm{MMN}-$ LTO/C shown in the insets to panels $\mathrm{a}$ and $\mathrm{b}$ in Figure 3, respectively. Both samples exhibited a bimodal pore size distribution with two narrow peaks. The smaller pores of both samples centered at about 3.5 are mainly contributed by the pores existing in the CMK-3 template. The large pores of MMN-TO/C and MMN-LTO/C are centered at 11.2 and $13.1 \mathrm{~nm}$, respectively, where its represent the space between nanoparticles. The abundant pore structure in micro/nano 

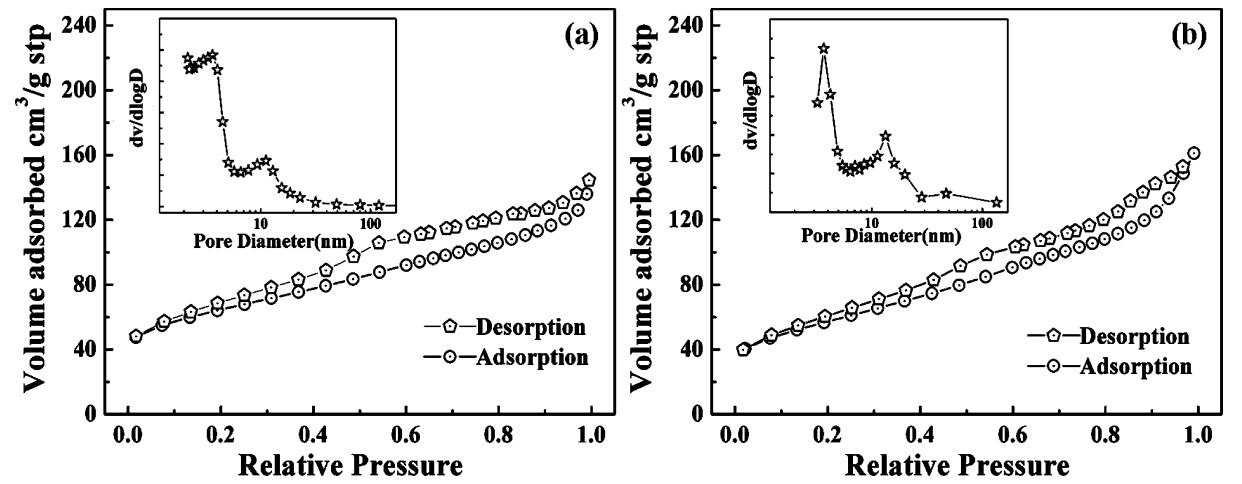

Figure 3. $\mathrm{N}_{2}$ adsorption-desorption isotherm of (a) MMN-TO/C and (b) MMN-LTO/C. The inset shows the pore size distribution calculated using the $\mathrm{BJH}$ method.
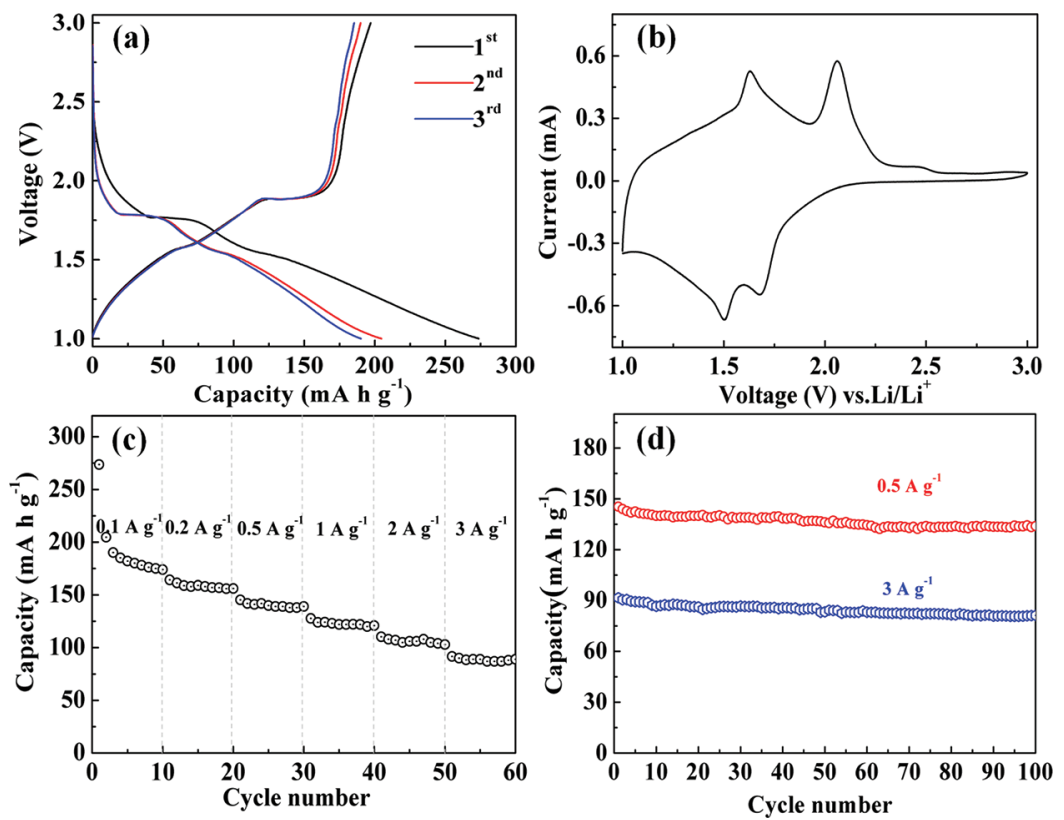

Figure 4. Electrochemical characterization of MMN-TO/C. (a) The first 3 cycles galvanostatic charge-discharge curves at a current density of 0.1 $\mathrm{A} \mathrm{g}^{-1}$, (b) representative CVs at a scan rate of $0.5 \mathrm{mV} \mathrm{s}^{-1}$, (c) rate performance at different current density, and (d) cycling performance at current density of $0.5 \mathrm{~A} \mathrm{~g} \mathrm{~g}^{-1}, 3 \mathrm{~A} \mathrm{~g}^{-1}$. All cycling measurements were conducted within a voltage window of $1.0-3.0 \mathrm{~V}$.

composite offers the potential to improve the electrochemical properties, in which electrolyte can easily infiltrate into the mesopores to contact the embedded nanocrystals.

The electrochemical performance of $\mathrm{MMN}-\mathrm{TO} / \mathrm{C}$ was evaluated in lithium half-cells first (Figure 4). The first 3 cycles galvanostatic charge-discharge curves for $\mathrm{MMN}-\mathrm{TO} / \mathrm{C}$ composite at a current density of $0.1 \mathrm{~A} \mathrm{~g}^{-1}$ are shown in Figure 4 a. Two pair distinct voltage plateaus can be observed in the charge-discharge curves, which imply that there are two steps for lithium insertion/extraction the material. The MMNTO/C delivered the first discharge capacity, approximately $273.6 \mathrm{~mA} \mathrm{~h} \mathrm{~g}^{-1}$. On charging, the capacity reached only 197.1 $\mathrm{mA} \mathrm{h} \mathrm{g}{ }^{-1}$, of which the large irreversible capacity between charge and discharge corresponds to $76.5 \mathrm{~mA} \mathrm{~h} \mathrm{~g}$. Several factors may be responsible for the low initial Coulombic efficiency (72\%). Consumption of lithium ions may be partially attributed to the insertion of lithium ions with the physiadsorbed water on $\mathrm{TiO}_{2}$ resulting in the formation of $\mathrm{Li}_{2} \mathrm{O}$ on the surface. ${ }^{57,58}$ Another reason may be ascribed to the $\mathrm{Li}$ being inserted into irreversible sites, such as surface vacancies or voids, either in anatase and/or in $\mathrm{TiO}_{2}-\mathrm{B} .{ }^{59}$ Further, the
CMK-3 template have large initial irreversible capacity due to its high surface area. ${ }^{60}$ However, in the subsequent two cycles, the discharge/charge curves are gradually coincided with each other, indicating a lower irreversible capacity and a higher Coulombic efficiency. Figure $4 \mathrm{~b}$ shows the representative cyclic voltammograms (CVs) of $\mathrm{MMN}-\mathrm{TO} / \mathrm{C}$ electrode at a scan rate of $0.5 \mathrm{mV} \mathrm{s}^{-1}$ in the voltage range of $1.0-3.0 \mathrm{~V}$. Consistent with the above galvanostatic charge-discharge analysis, two pairs of redox peaks can be observed. The pair of sharp redox peaks at 1.68 and $2.06 \mathrm{~V}$ is attributed to lithium insertion/ extraction with respect to the anatase phase whereas the other pair of broad redox peaks at 1.50 and $1.63 \mathrm{~V}$ is assigned to $\mathrm{TiO}_{2}-\mathrm{B}$ phase. The rate performances of $\mathrm{MMN}-\mathrm{TO} / \mathrm{C}$ at the current density of $0.1-3 \mathrm{~A} \mathrm{~g}^{-1}$ is show in Figure 4c. At lower current density, the discharge capacities at 0.2 and $0.5 \mathrm{~A} \mathrm{~g}^{-1}$ are around 164.2 and $145.3 \mathrm{~mA} \mathrm{~h} \mathrm{~g}^{-1}$, respectively. It can still retain 110.6 and $91.7 \mathrm{~mA} \mathrm{~h} \mathrm{~g}^{-1}$ at 2 and $3 \mathrm{~A} \mathrm{~g}^{-1}$, respectively. The electrochemical properties is better than pure $\mathrm{TiO}_{2}{ }^{16}$ carbon coating $\mathrm{TiO}_{2}$ particle, ${ }^{19}$ mesoporous $\mathrm{TiO}_{2} / \mathrm{C}$ synthesized by soft template method. ${ }^{52}$ The cycling performance of MMN$\mathrm{TO} / \mathrm{C}$ was then investigated under different current density 

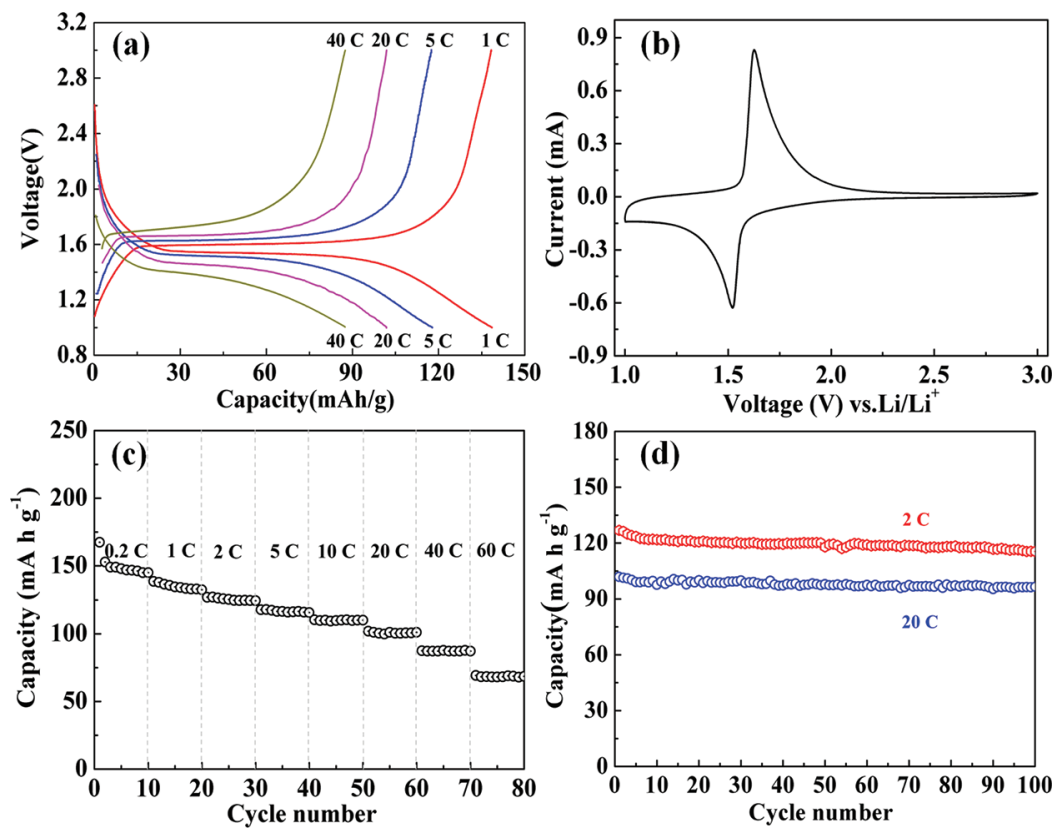

Figure 5. Electrochemical characterization of MMN-LTO/C. (a) The first-cycle charge-discharge voltage profiles at different current rates, (b) representative CVs at a scan rate of $0.5 \mathrm{mV} \mathrm{s}^{-1}$, (c) rate performance at different current rates, and (d) cycling performance at current rates of $2 \mathrm{C}$, 20 C. All cycling measurements were conducted within a voltage window of 1.0-3.0 V.

(after 10 cycles at $0.2 \mathrm{~A} \mathrm{~g}^{-1}$ ). In Figure $4 \mathrm{~d}$, the charge/ discharge capacities are displayed as a function of the number of cycles. Remarkably, at a current density $0.5 \mathrm{~A} \mathrm{~g}^{-1}$, a reversible capacity of $133.9 \mathrm{~mA} \mathrm{~h} \mathrm{~g}^{-1}$ was retained after 100 cycles. When a higher current density of $3 \mathrm{~A} \mathrm{~g}^{-1}$ is employed, a reversible capacity of $81.2 \mathrm{~mA} \mathrm{~h} \mathrm{~g}^{-1}$ can still be obtained after 100 cycles, which corresponds to only $0.11 \%$ capacity loss per cycle. Evidently, the electrochemical studies demonstrate that the $\mathrm{MMN}-\mathrm{TO} / \mathrm{C}$ exhibit a superior reversible capacity, excellent cycling performance, and good rate capability.

We also investigated the electrochemical properties of MMN-LTO/C for application as potential anode materials for LIBs. Figure 5a shows the charge/discharge voltage profiles of the MMN-LTO/C at different rate between 1.0 and $3.0 \mathrm{~V}$. It is evident that the discharge process of the MMN-LTO/C consists of three stages; the first stage is the quick voltage drop, the second stage is the distinct voltage plateau, and the third stage is a gradual decay in potential. The plateaus are related to the phase transition between the spinel $\mathrm{Li}_{4} \mathrm{Ti}_{5} \mathrm{O}_{12}$ and rock-salt type $\mathrm{Li}_{7} \mathrm{Ti}_{5} \mathrm{O}_{12}$ phases with $\mathrm{Li}$ insertion/extraction. With the increase of charge-discharge rates, there is a considerable drop in capacity values together with a drop in discharge voltage plateau, which are associated to the sluggish Li-ion diffusion kinetics at very high rates. Figure $5 \mathrm{~b}$ shows the $\mathrm{CVs}$ curve of the $\mathrm{MMN}-\mathrm{LTO} / \mathrm{C}$ electrode at a scan rate of $0.5 \mathrm{mV} \mathrm{s}^{-1}$, within the potential window of $1.0-3.0 \mathrm{~V}\left(\mathrm{vs} \mathrm{Li} / \mathrm{Li}^{+}\right)$. A pair of well-defined redox current peaks is observed at about 1.62 and $1.52 \mathrm{~V}$ during the cathodic and anodic sweeps. These peaks signify the redox reaction of $\mathrm{Ti}^{4+} / \mathrm{Ti}^{3+}$, which is demonstrated in reaction mechanism eq $1 .^{61}$

$$
\mathrm{Li}_{4} \mathrm{Ti}_{5} \mathrm{O}_{12}+3 \mathrm{Li}^{+}+3 \mathrm{e} \underset{\text { charge }}{\stackrel{\text { discharge }}{\rightleftarrows}} \mathrm{Li}_{7} \mathrm{Ti}_{5} \mathrm{O}_{12}
$$

The rate performances of $\mathrm{MMN}-/ \mathrm{C}$ at the rate of $0.2-60 \mathrm{C}$ is show in Figure 5c. At the initial lower rate of $0.2 \mathrm{C}$, the MMNLTO/C give a discharge capacity of $167.4 \mathrm{~mA} \mathrm{~h} \mathrm{~g}^{-1}$ during the first cycle with a Coulombic efficiency of $\sim 91 \%$. The
Coulombic efficiency is not high for LTO, which might be ascribed to irreversible capacity of CMK-3 and breakdown processes in the electrolyte solution during the initial cycles. The specific discharge capacity was slightly reduced to 138.6 , $117.9,110.3$, and $101.9 \mathrm{~mA} \mathrm{~h} \mathrm{~g}^{-1}$ at the current rates of $1,5,10$ and $20 \mathrm{C}$, respectively. Even at a high current rate of $60 \mathrm{C}$, a reversible capacity of $69.2 \mathrm{~mA} \mathrm{~h} \mathrm{~g}^{-1}$ could still be delivered, nicely confirming that the MMN-LTO/C has an advantage of building up a good ionic and electronic conduction net in the electrode. Figure 5d displays the high reversibility of the underlying electrochemical reactions over many chargedischarge cycles, at different current densities ( $\mathrm{C}$ rates). The discharge capacity in the first cycle was $126.8 \mathrm{~mA} \mathrm{~h} \mathrm{~g}^{-1}$ at the rate of $2 \mathrm{C}$, after 100 cycles with $8.2 \%$ capacity loss. A further increase in the C-rate to $20 \mathrm{C}$ led to decrease in capacity, but a reversible capacity of $96.5 \mathrm{~mA} \mathrm{~h} \mathrm{~g}^{-1}$ can still be obtained after 100 cycles, which corresponds to only $0.05 \%$ capacity loss per cycle. This result demonstrates that the structure of the composite is very stable, and the electrochemical $\mathrm{Li}^{+}$insertion/ extraction process is quite reversible even at high rates.

The impressive electrochemical performance of $\mathrm{MMN}-\mathrm{TO} /$ $\mathrm{C}(\mathrm{MMN}-\mathrm{LTO} / \mathrm{C})$ is ascribed to its unique nanostructure (Scheme 2). The mesopore carbon matrix not only creates a conductive matrix that enables fast electron transport between nano-active material but also effectively suppressed the undesired particle growth during the annealing in the present synthesis. The ultrafine nanoactive materials are highly dispersed in a mesopore carbon matrix, to building up a better ionic and electronic conduction net in the electrode layer. Furthermore, the mesoporous channel may facilitate electrolyte ion diffusion to active sites with less resistance.

\section{CONCLUSIONS}

In summary, mesoporous, micro/nano $\mathrm{TiO}_{2} / \mathrm{C}$ composite were rationally designed and successfully fabricated by using a nanocasting technique, in which the precursors solution can easily penetrate into the mesopores channel of surface-oxidized 
Scheme 2. Schematic Representation Showing That the Mesoporous, Micro/Nanostructure Favors Both Li Storage and Fast Electrode Kinetics

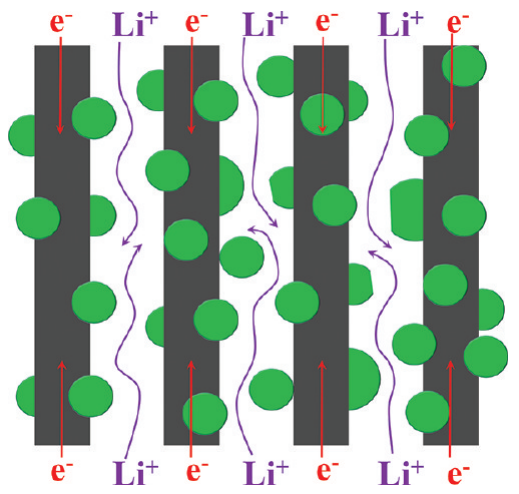

CMK-3 and followed by controlled hydrolysis. After chemical lithiation and a short post-annealing procedure, the $\mathrm{TiO}_{2}$ nanoparticles embedded in mesoporous carbon matrix were transformed in situ into $\mathrm{Li}_{4} \mathrm{Ti}_{5} \mathrm{O}_{12}$ to form highly conductivity MMN-LTO/C. In this way, the $\mathrm{TiO}_{2}$ or $\mathrm{Li}_{4} \mathrm{Ti}_{5} \mathrm{O}_{12}$ nanoparticles are uniformly dispersed and exclusively confined in interconnected mesoporous carbon matrix with highly electronic connectivity. Meanwhile, the composite retain the high and open mesoporosity, which ensures facile infitration of electrolyte into the mesopores in lithium ion cells. By combining such fascinating features, the $\mathrm{MMN}-\mathrm{TO} / \mathrm{C}$ and MMN-LTO/C show excellent electrochemical performance for LIBs (improved rate capability and good cycling properties), implying its potential application as an anode material for future LIBs.

\section{ASSOCIATED CONTENT}

\section{S Supporting Information}

Experimental details, Raman spectrum, EDS, $\mathrm{N}_{2}$ adsorptiondesorption isotherm. This material is available free of charge via the Internet at http://pubs.acs.org.

\section{AUTHOR INFORMATION}

\section{Corresponding Author}

*E-mail: azhangxg@nuaa.edu.cn (X.G.Z.); gzcao@u. washington.edu (G.Z.C.).

Notes

The authors declare no competing financial interest.

\section{ACKNOWLEDGMENTS}

This work is financially supported in part by the National Natural Science Foundations of China (21173120), the National Science Foundation of the U.S. (DMR-0605159, CMMI-1030048), Natural Science Foundations of Jiangsu Province (BK2011030), and Specialized Research Fund for the Doctoral Program of Higher Education of China (20060287026). L.S. also thanks the Jiangsu Innovation Program for Graduate Education (CXZZ11_0204) and Outstanding Doctoral Dissertation in NUAA (BCXJ11-10) for financial support and the China Scholarship Council (CSC) for providing a scholarship for Ph.D. study at the University of Washington.

\section{REFERENCES}

(1) Recham, N.; Chotard, J. N.; Dupont, L.; Delacourt, C.; Walker, W.; Armand, M.; Tarascon, J. M. Nat. Mater. 2010, 9, 68.

(2) Yang, Z. G.; Zhang, J. L.; Kintner-Meyer, M. C. W.; Lu, X. C.; Choi, D.; Lemmon, J. P.; Liu, J. Chem. Rev. 2011, 111, 3577.

(3) Wang, Y.; Cao, G. Z. Adv. Mater. 2008, 20, 2251.

(4) Yang, S. B.; Feng, X. L.; Müllen, K. Adv. Mater. 2011, 23, 3575.

(5) Guo, B. K.; Wang, X. Q.; Fulvio, P. F.; Chi, M. F.; Mahurin, S. M.; Sun, X. G.; Dai, S. Adv. Mater. 2011, 23, 4661.

(6) Park, K. S.; Benayad, A.; Kang, D. J.; Doo, S. G. J. Am. Chem. Soc. 2008, 130, 14930.

(7) Amine, K.; Belharouak, I.; Chen, Z. H.; Tran, T.; Yumoto, H.; Ota, N.; Myung, S. T.; Sun, Y. K. Adv. Mater. 2010, 22, 3052.

(8) Chen, J. S.; Tan, Y. L.; Li, C. M.; Cheah, Y. L.; Luan, D. Y.; Madhavi, S.; Boey, F. Y. C.; Archer, L. A.; Lou, X. W. J. Am. Chem. Soc. 2010, 132, 6124.

(9) Liu, J.; Cao, G. Z.; Yang, Z. G.; Wang, D. H.; Dubois, D.; Zhou, X. D.; Graff, G. L.; Pederson, L. R.; Zhang, J. G. ChemSusChem 2008, 1,676 .

(10) Shen, L. F.; Zhang, X. G.; Uchaker, E.; Yuan, C. Z.; Cao, G. Z. Adv. Energy Mater. 2012, DOI: 10.1002/aenm.201100720.

(11) Wagemaker, M.; Kentgens, A. P. M.; Mulder, F. M. Nature 2002, 418, 397.

(12) Ji, L. W.; Lin, Z.; Alcoutlabi, M.; Zhang, X. W. Energy Environ. Sci. 2011, 4, 2682.

(13) Li, H. S.; Shen, L. F.; Zhang, X. G.; Nie, P.; Chen, L.; Xu, K. J. Electrochem. Soc. 2012, 159, A426.

(14) Yue, W. B.; Randorn, C.; Attidekou, P. S.; Su, Z. X.; Irvine, J. T. S.; Zhou., W. Z. Adv. Funct. Mater. 2009, 19, 2826.

(15) Wagemaker, M.; Borghols, W. J. H. F.; Mulder, M. J. Am. Chem. Soc. 2007, 129, 4323.

(16) Wang, D. H.; Choi, D.; Yang, Z. G.; Viswanathan, V. V.; Nie, Z. M.; Wang, C. M.; Song, Y. J.; Zhang, J. G.; Liu, J. Chem. Mater. 2008, 20, 3435 .

(17) Myung, S. T.; Takahashi, N.; Komaba, S.; Yoon, C. S.; Sun, Y. K.; Amine, K.; Yashiro, H. Adv. Funct. Mater. 2011, 21, 3231.

(18) Shen, L. F.; Zhang, X. G.; Li, H. S.; Yuan, C. Z.; Cao, G. Z. J. Phys. Chem. Lett. 2011, 2, 3096.

(19) Ding, S. J.; Chen, J. S.; Luan, D. Y.; Boey, F. Y. C.; Madhavibc, S.; Lou, X. W. Chem. Commun. 2011, 47, 5780.

(20) Das, S. K.; Darmakolla, S.; Bhattacharyya, A. J. J. Mater. Chem. 2010, 20, 1600 .

(21) Deng, D.; Kim, M. G.; Lee, J. Y.; Cho, J. Energy Environ. Sci. 2009, 2, 818.

(22) Liu, H. S.; Bi, Z. H.; Sun, X. G.; Unocic, R. R.; Paranthaman, M. P.; Dai, S.; Brown, G. M. Adv. Mater. 2011, 23, 3450.

(23) Yang, Z. X.; Du, G. D.; Guo, Z. P.; Yu, X. B.; Chen, Z. X.; Guo, T. L.; Sharma, N.; Liu, H. K. Electrochem. Commun. 2011, 13, 46.

(24) Armstrong, G.; Armstrong, A. R.; Bruce, P. G.; Reale, P.; Scrosati, B. Adv. Mater. 2006, 18, 2597.

(25) Amatucci, G. G.; Badway, F.; Pasquier, A. D.; Zheng, T. J. Electrochem. Soc. 2001, 148, A930.

(26) Ohzuku, T.; Ueda, A.; Yamamoto, N. J. Electrochem. Soc. 1995, $142,1431$.

(27) Ferg, E.; Gummow, R. J.; Dekock, A.; Thackeray, M. M. J. Electrochem. Soc. 1994, 141, L147.

(28) Shen, L. F.; Yuan, C. Z.; Luo, H. J.; Zhang, X. G.; Yang, S. D.; Lu, X. J. Nanoscale 2011, 3, 572.

(29) Cheng, L.; Liu, H. J.; Zhang, J. J.; Xiong, H. M.; Xia, Y. Y. J. Electrochem. Soc. 2006, 153, A1472.

(30) Prakash, A. S.; Manikandan, P.; Ramesha, K.; Sathiya, M.; Tarascon, J. M.; Shukla, A. K. Chem. Mater. 2010, 22, 2857.

(31) Jo, M. R.; Nam, K. M.; Lee, Y.; Song, K.; Park, J. T.; Kang, Y. M. Chem. Commun. 2011, 47, 11474.

(32) Cao, F. F.; Guo, Y. G.; Zheng, S. F.; Wu, X. L.; Jiang, L. Y.; Bi, R. R.; Wan, L. J.; Maier, J. Chem. Mater. 2010, 22, 1908.

(33) Zhao, L.; Hu, Y. S.; Li, H.; Wang, Z.; Chen, L. Adv. Mater. 2011, 23,1385 . 
(34) Jung, H. G.; Jang, M. W.; Hassoun, J.; Sun, Y. K.; Scrosati, B. Nat Commun 2011, 2, 516.

(35) Jung, H. G.; Myung, S. T.; Yoon, C. S.; Son, S. B.; Oh, K. H.; Amine, K.; Scrosati, B.; Sun, Y. K. Energy Environ. Sci. 2011, 4, 1345.

(36) Lin, Y. S.; Duh, J. G. J. Power Sources 2011, 196, 10698.

(37) Cheng, L.; Yan, J.; Zhu, G. N.; Luo, J. Y.; Wang, C. X.; Xia, Y. Y. J. Mater. Chem. 2010, 20, 595.

(38) Shen, L. F.; Yuan, C. Z.; Luo, H. J.; Zhang, X. G.; Xu, K.; Zhang, F. J. Mater. Chem. 2011, 21, 761.

(39) Li, C. C.; Li, Q. H.; Chen, L. B.; Wang, T. H. ACS Appl. Mater. Interfaces 2012, 4, 1233.

(40) Guo, Y. G.; Hu, Y. S.; Sigle, W.; Maier, J. Adv. Mater. 2007, 19, 2087.

(41) Huang, S. H.; Wen, Z. Y.; Zhu, X. J.; Lin, Z. X. J. Power Sources 2007, 165, 408.

(42) Borghols, W. J. H.; Wagemaker, M.; Lafont, U.; Kelder, E. M.; Mulder, F. M. J. Am. Chem. Soc. 2009, 131, 17786.

(43) Lim, J.; Choi, E.; Mathew, V.; Kim, D.; Ahn, D.; Gim, J.; Kang, S. H.; Kim, J. J. Electrochem. Soc. 2011, 158, A275.

(44) Kavan, L.; Prochazka, J.; Spitler, T. M.; Kalbac, M.; Zukalova, M. T.; Drezen, T.; Gratzel, M. J. Electrochem. Soc. 2003, 150, A1000.

(45) Shen, L. F.; Yuan, C. Z.; Luo, H. J.; Zhang, X. G.; Xu, K.; Xia, Y. Y. J. Mater. Chem. 2010, 20, 6998.

(46) Shen, L. F.; Yuan, C. Z.; Luo, H. J.; Zhang, X. G.; Chen, L.; Li, H. S. J. Mater. Chem. 2011, 21, 14414.

(47) Ren, Y.; Armstrong, A. R.; Jiao, F.; Bruce, P. G. J. Am. Chem. Soc. 2010, 132, 996.

(48) Sorensen, E. M.; Barry, S. J.; Jung, H. K.; Rondinelli, J. M.; Vaughey, J. T.; Poeppelmeier., K. R. Chem. Mater. 2006, 18, 482.

(49) Haetge, J.; Hartmann, P.; Brezesinski, K.; Janek, J.; Brezesinski, T. Chem. Mater. 2011, 23, 4384.

(50) Ji, X. L.; Herle, P. S.; Rho, Y.; Nazar, L. F. Chem. Mater. 2007, 19, 374.

(51) Wang, G. X.; Liu, H.; Liu, J.; Qiao, S. Z.; Lu, G. Q.; Munroe, P.; Ahn, H. Adv. Mater. 2010, 22, 4944.

(52) Liang, C. D.; Dudney, N. J.; Howe, J. Y. Chem. Mater. 2009, 21, 4724.

(53) Ishii, Y.; Kanamori, Y.; Kawashita, T.; Mukhopadhyay, I.; Kawasaki, S. J. Phy. Chem. Solids 2010, 71, 511.

(54) Kang, E.; Jung, Y. S.; Kim, G. H.; Chun, J. Y.; Wiesner, U.; Dillon, A. C.; Kim, J. K.; Lee, J. Adv. Funct. Mater. 2011, 21, 4349.

(55) Fang, B. Z.; Kim, M. S.; Kim, J. H.; Lim, S.; Yu, J. S. J. Mater. Chem. 2010, 20, 10253.

(56) Lee, J. S.; Joo, S. H.; Ryoo, R. J. Am. Chem. Soc. 2002, 124, 1156.

(57) Ding, S. J.; Chen, J. S.; Lou., X. W. Adv. Funct. Mater. 2011, 21, 4120.

(58) Das, S. K.; Bhattacharyya, A. J. J. Phys. Chem. C 2009, 113, 17367.

(59) Shin, J. Y.; Samuelis, D.; Maier, J. Adv. Funct. Mater. 2011, 21, 3464.

(60) Das, S. K.; Bhattacharyya, A. J. J. Electrochem. Soc. 2011, 158, A705.

(61) Zhou, H. S.; Zhu, S. M.; Hibino, M.; Honma, I.; Ichihara, M. Adv. Mater. 2003, 15, 2107.

(62) Scharner, S.; Weppner, W.; Schmid-Beurmann, P. J. Electrochem. Soc. 1999, 146, 857. 